Disclosure of Interest: None declared

DOI: 10.1136/annrheumdis-2018-eular.6489

\section{FRI0245 2 PREDICTORS FOR CLINICALLY DIAGNOSED GOUT - 30 YEARS FOLLOW-UP IN THE MALMÖ PREVENTIVE PROJECT COHORT, SWEDEN}

M.C Kapetanovic ${ }^{1}$, P. Nilsson ${ }^{2}$, C. Turesson ${ }^{3}$, M. Englund ${ }^{4}$, N. Dalbeth ${ }^{5}$, L. Jacobsson ${ }^{6}$. 1 Department of Clinical Sciences Lund, Lund University, rheumatology, Lund; ${ }^{2}$ Lund University, Malmö, Sweden; Internal Medicine and Skåne University Hospital, Internal medicine; ${ }^{3}$ Lund University, Department of Clinical Sciences, Malmö, Lund University and Skåne University Hospital, rheumatology, Malmö; ' Department of Clinical Sciences Lund, Lund University, Clinical Epidemiology Unit, Orthopaedics, Lund, Sweden; ${ }^{5}$ University of Auckland, Department of Medicine, Auckland, New Zealand; ${ }^{6}$ Department of Rheumatology and Inflammation Research, Sahlgrenska Academy at University of Gothenburg, Gothenburg, Sweden

Background: Gout is the most common form of inflammatory arthritis worldwide. Hyperuricemia is a crucial risk factor. The relative importance of other risk factors is slightly more controversial.

Objectives: Our aim was to identify predictors for clinical gout cohort from a population survey, the Malmö Preventive Project (MPP) - a large-scale screening and case finding program in Malmö, Sweden.

Methods: A total of 33346 individuals ( $67 \%$ men, mean age 46 years, mean follow-up 28 years) were screened 1974-1992. The survey included: A Questionnaire (alcohol consumption, smoking); A Physical Examination and Laboratory tests. The Malmö modification of Michigan alcoholism screenings test (MmMAST) was used to identify alcohol risk consumption (Mm-MAST score $\geq 2$ ). Subjects were followed to date of first gout diagnosis, death, migration from area, or December 2014. All gout diagnoses given at visits to physicians in primary or specialised care were identified by linking MPP cohort to regional Skåne Healthcare Register and to National Patient Register. Possible risk factors/markers at baseline associated with incident gout were analysed using Cox-regression models. Results: In total, 1275 individuals (3.8\%); 1014 men (4.5\%) and 261 women (2.4\%) were diagnosed with gout. In both sexes, baseline s-UA >405 (ageadjusted) was the strongest factor associated with incident gout. Higher age, higher BMI, higher s-triglycerides, hypertension and smoking were also associated with gout in both sexes. Mm-MAST score $\geq 2$ was associated with gout only in men while higher ESR was associated with gout only in women (table 1).

Conclusions: In this large cohort of middle-age individuals, hyperuricemia, higher age, hypertriglyceridemia and higher BMI were associated with incident gout in both sexes. Alcohol risk consumption predicted gout only in men. Higher ESR, as a possible marker of chronic inflammation, was a significant predictor only in women.

Disclosure of Interest: None declared
DOI: 10.1136/annrheumdis-2018-eular.2987

\begin{tabular}{|l|l}
\hline FRI0246 & INVESTIGATING THE EFFECT OF SERUM URATE \\
& LEVELS ON GOUT FLARE RATES IN A LARGE-SCALE \\
& U.S. ADMINISTRATIVE CLAIMS DATABASE
\end{tabular}

P. Herzog ${ }^{1,2}$, A.-C. Fu ${ }^{1}$, J. Lim ${ }^{1,3}$, D.C. Taylor ${ }^{1} .{ }^{1}$ Ironwood Pharmaceuticals, Inc., Cambridge; ${ }^{2}$ Columbia University Mailman School of Public Health, New York;

${ }^{3}$ Tufts University School of Medicine, Boston, USA

Background: Reducing patients' serum urate (sUA) levels has long been the focus of gout treatments. Current evidence suggests that sUA levels $\geq 6.0 \mathrm{mg} / \mathrm{dL}$ significantly increase a subject's risk of an acute gout attack or "flare."

Objectives: To investigate the effects of sUA levels on gout flare rates (GFLR) over a 5 year period in a large-scale US commercial claims database.

Methods: Truven MarketScan administrative claims data from 2010 to 2015 were used for this analysis. The study population was patients with gout whose index gout diagnosis was defined as first gout diagnosis. Index sUA date (IsD) was defined as the SUA result closest to, but not preceding, a subject's index gout diagnosis. Patients were included if they had continuous health plan enrollment during the year prior to and after their IsD. Patients without an SUA result after their index gout diagnosis were excluded. Three sUA comparison groups were created based on mean sUA values calculated from sUA measurements at ISD through follow-up. Person-time was defined as time between IsD to the end of continuous enrollment or to the end of the study period, whichever came first. Gout flares were determined via a published algorithm Halpern 2009 combining health care visits and prescriptions by using ICD9/10, HCPCS, and NDC codes. Subjects' annual GFLR were calculated as their number of flares per person-time. Mean GFLR were calculated for each sUA comparison group. A generalised linear model was developed to investigate the effect of sUA levels on GFLR after adjusting for demographics and regions.

Results: 15140 subjects were included in the analysis. Most subjects were male $(78 \%)$ and from the south $(47 \%)$ with a mean age of 52 years. Mean sUA was $6.9 \mathrm{mg} / \mathrm{dL}(\mathrm{min}=1.4, \mathrm{max}=17.5)$ where $58 \%$ of patients had sUA between 6.0 and $9.0 \mathrm{mg} / \mathrm{dL}$. Subjects were followed for 2.1 years on average. sUA $\geq 6.0$ and $<9.0$ $\mathrm{mg} / \mathrm{dL}$ (Group 2), and sUA $\geq 9.0 \mathrm{mg} / \mathrm{dL}$ (Group 3) were both associated with increased gout flare rates compared to sUA $<6.0 \mathrm{mg} / \mathrm{dL}$ (Group 1). Group $3 \mathrm{had}$ 1.540 times of the annual flare rate of Group 1. Male sex and increasing age were associated with increased GFLR. North central, south, and west US regions were all positively associated with GFLR in relation to the northeast (table 1).

Abstract FRI0245 - Table 1

\begin{tabular}{|c|c|c|c|c|c|}
\hline \multirow[t]{9}{*}{$\begin{array}{l}\text { MEN ( } n=22433) \text { where } 1014 \text { had incident } \\
\text { gout }\end{array}$} & $\begin{array}{c}\text { Baseline variables } s-U A>405 \mu \mathrm{mol} / \\
L(\text { yes }, \%)\end{array}$ & $\begin{array}{l}\text { Mean } \\
\text { (SD) }\end{array}$ & $\begin{array}{c}\text { Frequency (yes,\%) } \\
10.1 \%\end{array}$ & $\begin{array}{c}\mathrm{HR}(95 \% \mathrm{Cl})^{\star} \text { (age adjusted) } 5.4 \\
(4.8-6.2)\end{array}$ & $\begin{array}{c}\text { HR }(95 \% \mathrm{Cl}) \\
\left(\text { multivariate analysis }{ }^{\star \star}\right) 4.1 \\
(3.4-4.9)\end{array}$ \\
\hline & Age (years) & $\begin{array}{l}43.7 \\
(6.6)\end{array}$ & & $1.4(1.3-1.5)$ & $1.4(1.2-1.5)$ \\
\hline & Body mass index $\left(\mathrm{kg} / \mathrm{m}^{2}\right)$ & $\begin{array}{l}24.7 \\
(3.3)\end{array}$ & & $1.4(1.4-1.5)$ & $1.3(1.2-1.4)$ \\
\hline & e-GFR (ml/min) & $\begin{array}{c}79.1 \\
(10.5)\end{array}$ & & $0.9(0.8-0.9)$ & $0.9(0.8-1.0)$ \\
\hline & $\mathrm{s}$-triglycerides (mmol/L) & $1.5(1.1)$ & & $1.1(1.1-1.2)$ & $1.1(1.0-1.1)$ \\
\hline & ESR $\mathrm{mm} / \mathrm{hour}$ & $5.9(5.7)$ & & $1.0(0.9-1.1)$ & $1.0(0.9-1.1)$ \\
\hline & Hypertension (yes,\%) & & $16.4 \%$ & $1.7(1.5-2.0)$ & $1.3(1.1-1.5)$ \\
\hline & CVD at baseline (yes/no) & & $2.1 \%$ & $1.7(1.1-2.8)$ & $1.4(0.9-2.3)$ \\
\hline & Smoking (yes/no) & & $49.2 \%$ & $1.1(1.0-1.3)$ & $1.3(1.1-1.6)$ \\
\hline Mm-MAST $\geq 2$ (yes,\%) & & $30.8 \%$ & $1.5(1.3-1.7)$ & $1.3(1.1-1.5)$ & \\
\hline WOMEN ( $n=10902)$ in where 261 had & $\mathrm{s}-U \mathrm{~A}>405 \mu \mathrm{mol} / \mathrm{L}(\mathrm{yes}, \%)$ & & $1.5 \%$ & $12.5(8.6-18.1)$ & $5.9(2.2-15.9)$ \\
\hline \multirow[t]{9}{*}{ incident gout } & Age (years) & $\begin{array}{l}49.7 \\
(7.4)\end{array}$ & & $1.7(1.5-2.1)$ & $1.3(1.1-1.6)$ \\
\hline & BMI $\left(\mathrm{kg} / \mathrm{m}^{2}\right)$ & $\begin{array}{l}24.4 \\
(4.2)\end{array}$ & & $1.6(1.5-1.8)$ & $1.6(1.6-2.0)$ \\
\hline & eGFR (ml/min) & $\begin{array}{c}75.6 \\
(10.9)\end{array}$ & & $0.8(0.7-0.9)$ & $0.8(0.6-1.0)$ \\
\hline & $\mathrm{s}$-triglycerides $(\mathrm{mmol} / \mathrm{L})$ & $1.1(0.6)$ & & $1.3(1.2-1.4)$ & $1.2(1.0-1.5)$ \\
\hline & ESR (mm/hour) & $9.6(7.7)$ & & $1.3(1.2-1.4)$ & $1.2(1.0-1.5)$ \\
\hline & Hypertension (yes,\%) & & $22 \%$ & $2.0(1.6-2.0)$ & $1.1(0.6-1.9)$ \\
\hline & CVD at baseline (yes,\%) & & $3.4 \%$ & $2.1(1.3-3.6)$ & $3.0(0.7-12.3)$ \\
\hline & Smoking (yes,\%) & & $34.9 \%$ & $1.2(0.9-1.5)$ & $1.7(1.0-2.8)$ \\
\hline & Mm-MAST $\geq 2(y e s, \%)$ & & $2.8 \%$ & $1.3(0.6-2.6)$ & $1.2(0.6-2.4$ \\
\hline
\end{tabular}

${ }^{*} \mathrm{HR}$ is calculated per $1 \mathrm{SD}$ or for dichotomous covariates (yes vs. no) 
Abstract FRI0246 - Table 1. Generalised linear model for association between sUA level and gout flare rates $(n=15,140)$

\begin{tabular}{|c|c|c|c|}
\hline Variable & Rate Ratio & $95 \% \mathrm{Cl}$ & $p$-value \\
\hline Group 2: sUA 26.0 and $<9.0 \mathrm{mg} / \mathrm{dL}^{1}$ & 1.179 & $(1.143,1.216)$ & $<0.001$ \\
\hline Group 3: sUA $\geq 9.0 \mathrm{mg} / \mathrm{dL}^{1}$ & 1.540 & $(1.475,1.608)$ & $<0.001$ \\
\hline Sex: Male & 1.374 & $(1.326,1.424)$ & $<0.001$ \\
\hline Age & 1.012 & $(1.010,1.014)$ & $<0.001$ \\
\hline North central ${ }^{2}$ & 2.198 & $(2.114,2.285)$ & $<0.001$ \\
\hline South ${ }^{2}$ & 1.382 & $(1.339,1.425)$ & $<0.001$ \\
\hline West $^{2}$ & 2.038 & $(1.935,2.145)$ & $<0.001$ \\
\hline
\end{tabular}

Conclusions: These results suggest that higher sUA levels are associated with higher flare rates and that sUA level may be an indicator of GFLR. This finding may encourage health providers to prioritise reducing SUA levels in gout patients to reduce the frequency of gout flares and improve gout management.

\section{REFERENCES:}

[1] Halpern R, et al. The effect of serum urate on gout flares and their associated costs. J Clin Rheumatol 2009;15(1):3-7.

[2] Halpern R, et al. Impact of noncompliance with urate-lowering drug on serum urate and gout-related healthcare costs: administrative claims analysis. Curr Med Res Opin 2009;25(7):1711-1719.

[3] Abhishek A, et al. Association of serum uric acid and disease duration with frequent gout attacks: a case-control study. Arthritis Care Res (Hoboken) 2016;68(10):1573-1577.

[4] Sarawate CA, et al. Serum Urate Levels and Gout Flares. J Clin Rheumatol 2006;12(2):61-65.

Acknowledgements: Study funded by Ironwood Pharmaceuticals.

Disclosure of Interest: P. Herzog Employee of: Ironwood Pharmaceuticals, Inc., A.-C. Fu Employee of: Ironwood Pharmaceuticals, Inc., J. Lim Employee of: Ironwood Pharmaceuticals, Inc., D. Taylor Shareholder of: Ironwood Pharmaceuticals, Inc., Employee of: Ironwood Pharmaceuticals, Inc.

DOI: 10.1136/annrheumdis-2018-eular.6895

\section{FRI0247 GOUT CHARACTERISTICS AND ITS ASSOCIATION WITH THE PRESENCE OF CARDIOVASCULAR DISEASE: A CASE-CONTROL STUDY}

\section{S.J. Lopez Salguero, M. Andrés Collado. Reumatología, Hospital General} Universtiario Alicante, Alicante, Spain

Background: Gout is an independent risk factor for any type of cardiovascular disease (CVD). The exact mechanism behind remains to be elucidated, but persistent crystal-related inflammation is presumed as a key factor.

Objectives: The aim of this study was to assess whether gout characteristics that may indicate a more severe disease and higher inflammatory load are associated with the presence of CVD.

Methods: Case-control study, performed at baseline of an inception cohort including consecutive crystal-proven gout patients seen at a rheumatology unit. Gout features (time since first attack, number of attacks, number of joints affected, pattern of presentation, tophi) were registered after interview and physical exam. Presence and duration of CVD (which included coronary heart disease, heart failure, stroke or peripheral artery disease) was registered after interview and records review. Those patients who have suffered from CVD prior to the onset of gout were excluded. Other cardiovascular risk factors, as well as clinical and laboratory variables, were also registered. Odds ratios with 95\% confidence intervals $(95 \% \mathrm{Cl})$ for each gout feature were calculated between patients with and without CVD, using a multiple logistic regression model to adjust for confounders.

Results: The inception cohort includes 308 patients; 54 were excluded for this study because gout onset occurred after CVD, so finally 254 cases were analysed. Mean age was 61.4 years (SD 13.9), being 225 (88.6\%) men. Regarding gout, median duration was 5 years (IQR 1-12), median number of reported attacks was 5 (IQR 2-14) that had involved a median of 3 joints (IQR 2-5); presenting attack was monoarticular in $77.4 \%$ cases, oligoarticular in $16.7 \%$, and polyarticular in $6 \%$, and 58 patients $(22.8 \%)$ showed tophi at enrolment. A total of 32 patients (12.6\%) had suffered from CVD at enrolment. Table 1 shows the results of logistic regression analysis: time since first attack and polyarticular presentation of gout both significantly associated with the presence of CVD, while other variables showed no association. After multivariate analysis, time since first attack persisted associated with CVD, while polyarticular involvement showed a trend towards signification.

\begin{tabular}{|c|c|c|c|c|}
\hline \multicolumn{5}{|c|}{$\begin{array}{l}\text { Association between gout features and } \\
\text { cardiovascular disease }\end{array}$} \\
\hline & $\begin{array}{l}\text { Simple } \\
\text { regression }\end{array}$ & & $\begin{array}{l}\text { Multiple } \\
\text { regression }\end{array}$ & \\
\hline & $\begin{array}{c}\text { OR } \\
(95 \% \mathrm{Cl})\end{array}$ & $\mathrm{p}$ & $\begin{array}{c}\text { aOR } \\
(95 \% \mathrm{Cl})^{\star}\end{array}$ & $\mathrm{p}$ \\
\hline Gout duration & $\begin{array}{c}1.07(1.03- \\
1.10)\end{array}$ & $<0.001$ & $\begin{array}{l}1.06(1.02- \\
1.11)\end{array}$ & 0.005 \\
\hline Number of attacks suffered & $\begin{array}{c}1.00(0.99- \\
1.00)\end{array}$ & 0.561 & - & - \\
\hline Number of involved joints & $\begin{array}{c}1.09(0.96- \\
1.22)\end{array}$ & 0.177 & - & - \\
\hline \multicolumn{5}{|l|}{ Joint pattern at presentation } \\
\hline i. Monoarticular & $\begin{array}{c}1 . \\
\text { (ref) }\end{array}$ & - & 1.0 (ref) & - \\
\hline ii. Oligoarticular & $\begin{array}{l}2.30(0.93- \\
5.72)\end{array}$ & 0.073 & $\begin{array}{c}1.71(0.44- \\
6.65)\end{array}$ & 0.440 \\
\hline iii. Polyarticular & $\begin{array}{c}3.56(1.02- \\
12.32)\end{array}$ & 0.045 & $\begin{array}{c}5.33(0.92- \\
30.78)\end{array}$ & 0.061 \\
\hline Tophi & $\begin{array}{l}1.64(0.73- \\
3.69)\end{array}$ & 0.234 & - & - \\
\hline
\end{tabular}

*aOR: adjusted OR for age, gender, hypertension, diabetes, dyslipidemia, smok ing background, obesity, and renal failure.

Conclusions: Time since first attack and likely a polyarticular presentation, two variables that may estimate crystal and inflammatory load in gout patients, are independently associated with the presence of CVD, adding evidence to the role of persistent inflammation on its development.

Disclosure of Interest: None declared

DOI: 10.1136/annrheumdis-2018-eular.1448

\section{FRI0248 VALIDITY OF RANDOM URINARY URIC ACID-TO- CREATININE RATIO FOR ESTIMATING 24-HOUR URINE URIC ACID EXCRETION IN PATIENTS WITH GOUT}

S. Choi ${ }^{1}$, S.-J. Moon ${ }^{2}$, E.-J. Kang ${ }^{3}$, K.-H. Lee ${ }^{4} .{ }^{1}$ Internal Medicine, Chung-Ang University College of Medicine, Seoul, ${ }^{2}$ Internal Medicine, Catholic Kwandong University College of Medicine, Incheon; ${ }^{3}$ Internal Medicine, Busan Medical Center Busan; ${ }^{4}$ Internal Medicine, Dongguk University College of Medicine, Goyang, Korea, Republic Of

Background: Gout is one of a heterogeneous group of diseases related to hyperuricemia. The measurement of 24 hour urinary uric acid excretion is frequently used to evaluate disease status and select drugs that lower uric acid level. How ever, 24 hour urine collection is inconvenient and frequently unreliable, due to errors in collection. Therefore, a simpler alternative to the 24 hour urine collection is needed.

Objectives: We investigated the utility of the random urine uric acid-to-creatinine (UA/CR) ratio in predicting 24 hour urine uric acid excretion in patients with gout. Methods: Ninety patients with gout without any use of uric acid lowering agents were enrolled in this study. The mean age was $50.0 \pm 16.7$ years old and the male patient was $90.0 \%(81 / 90)$ of all participants. For the evaluation of uric acid excretion and renal function, patients were collected 24 hour urine. Random urine uric acid and creatinine specimens were gained on the same day of 24 hour urine collection. Chronic kidney disease was defined as a creatinine clearance (CCr) leve of less than $60 \mathrm{ml} / \mathrm{min} / 1.73 \mathrm{~m}^{2}$ measured in 24 hour urine collection sample. Excretion of more than $600 \mathrm{mg}$ of uric acid in the 24 hour urine sample was defined as uric acid over-excretion.

Results: Mean serum uric acid level was $7.73 \pm 1.89 \mathrm{mg} / \mathrm{dl}$, and the mean 24 hou uric acid excretion was $666.5 \pm 236.2 \mathrm{mg}$. The random urinary UA/CR ratio showed positive correlation with 24 hour urine uric acid excretion $(\gamma=0.398$, $\mathrm{p}<0.001)$. Correlation between these two variables was also found in the patients with chronic kidney disease $(\gamma=0.762, p=0.028$ In the linear regression analysis absolute 24 hour urine uric acid excretion was estimated to be $581 \times$ (random urinary $U A / C r)+432\left(p<0.001\right.$, adjusted $\left.R^{2}=0.398\right)$. The best cut-off value for the random urinary $\mathrm{UA} / \mathrm{Cr}$ ratio to distinguish between uric acid over-excretion and normal uric acid excretion was 0.342 , with a sensitivity of $74.1 \%$, specificity of $66.7 \%$. The areas under the curves (AUCs) of the random urine UA/CR ratio was 0.763 [95\% confidence interval $(\mathrm{Cl}), 0.665-0.861, \mathrm{p}<0.001]$.

Conclusions: The random urine UA/CR ratio correlated with 24 hour urine uric acid excretions in patients with gout. The best cut-off random urine UA/CR ratio value to discriminate uric acid over-excretion was 0.342 , with a sensitivity of $74.1 \%$ and a specificity of $66.7 \%$. The random urine UA/CR ratio would be a useful 